\title{
Involvement of Interleukin-1 in Immobilization Stress-Induced Increase in Plasma Adrenocorticotropic Hormone and in Release of Hypothalamic Monoamines in the Rat
}

\author{
Futoshi Shintani,, ${ }^{1,2}$ Toshio Nakaki, ${ }^{2}$ Shigenobu Kanba, ${ }^{1}$ Koichi Sato,, Gohei Yagi, ${ }^{1}$ Masahide Shiozawa, ${ }^{3}$ \\ Sadakazu Aiso, ${ }^{3}$ Ryuichi Kato, ${ }^{2}$ and Masahiro Asai ${ }^{1}$ \\ Departments of ${ }^{1}$ Neuro-psychiatry, ${ }^{2}$ Pharmacology, and ${ }^{3}$ Anatomy, Keio University School of Medicine, Tokyo 160, \\ Japan
}

We investigated whether interleukin-1 (IL-1) activity in the rat hypothalamus was increased by immobilization stress (IS), and whether pretreatment with an interleukin-1 receptor antagonist (IL-1Ra) is capable of inhibiting IS-induced elevations of hypothalamic norepinephrine (NE), dopamine (DA), and serotonin (5-HT) and the levels of their metabolites as well as of plasma adrenocorticotropic hormone (ACTH). IL-1 activity was estimated with a bioassay using mouse thymocyte proliferation in the presence of concanavalin A. IL-1Ra was administered directly into the anterior hypothalamus, and monoamines were determined using a microdialysis technique and an HPLC system. First, we found that levels of IL-1 activity in the rat hypothalamus reached a maximum at $60 \mathrm{~min}$ after starting IS. Second, IL1Ra $(2 \mu \mathrm{g})$ significantly inhibited IS-induced increases in hypothalamic NE, DA, and 5-HT levels as well as the levels of their metabolites. In addition, IL-1Ra ( $2 \mu \mathrm{g})$ also inhibited the IS-induced elevation of plasma ACTH levels. Third, timing effects of IL-1Ra administration on the IS-induced monoamines or ACTH responses were examined. IL-1Ra $(2 \mu \mathrm{g})$ administered at 5 or $60 \mathrm{~min}$ before the start of IS, but not at 5 or $60 \mathrm{~min}$ after IS had been started, exerted inhibitory effects on these responses, indicating that the effects of IL-1 occurred within 5 min after the initiation of IS. In summary, these results suggest that IS enhances biologically active IL-1 In the hypothalamus, and that hypothalamic IL-1 plays a role in the regulation of IS-induced responses including elevated monoamine release in the hypothalamus and activation of the hypothalamo-pituitary-adrenal axis. Moreover, since $5 \mathrm{~min}$ is too short a time for IS to induce production of IL-1, IS may augment the effects of preexisting IL-1 in the hypothalamus.

[Key words: interleukin-1 receptor antagonist, norepinephrine, dopamine, 5-HT, hypothalamo-pituitary-adrenal axis, immobilization stress, interleukin-1, adrenocorticotropic hormone, rat anterior hypothalamus]

\footnotetext{
Received Apr. 29, 1994; revised Aug. 26, 1994; accepted Sept. 6, 1994.

This work was supported in part by Keio Gijuku Academic Development Funds and Japan Health Sciences Foundation. We are grateful to Dr. Robert C. Thompson of Synergen, Inc., for gifts of IL-1Ra. We thank Dr. G. Wakabayashi of the Department of Surgery, Keio University School of Medicine, for his helpful advice.

Correspondence should be addressed to Futoshi Shintani, M.D., Department of Neuro-psychiatry, Keio University School of Medicine, Shinanomachi 35, Shinjuku-ku, Tokyo 160, Japan.

Copyright (C) 1995 Society for Neuroscience 0270-6474/95/151961-10\$05.00/0
}

It has been observed that various forms of physical stress elicit activation of the hypothalamo-pituitary-adrenal (HPA) axis and increase the release of monoamines in the brain (Johnson et al., 1992). Several studies have shown that interleukin-1 (IL-1) administered systemically stimulates secretion of corticotropin-releasing hormone (CRH) (Berkenbosch et al., 1987; Sapolsky et al., 1987), and activates the HPA axis (Barbanel et al., 1990; Berkenbosch et al., 1991; Besedovsky et al., 1991). On the other hand, we previously used in vivo brain microdialysis and a highperformance liquid chromatography electrochemical detection system to demonstrate that human recombinant IL-1 $\beta$ (hrIL-1 $\beta$ ), which had been administered directly into the rat anterior hypothalamus, facilitated release of norepinephrine (NE), dopamine (DA), and serotonin (5-HT) as well as their metabolites, 4-hydroxy-3-methoxyphenylglycol (MHPG), 3,4-dihydroxyphenylacetic acid (DOPAC), 4-hydroxy-3-methoxyphenylacetic acid (HVA), and 5-hydroxyindole-3-acetic acid (5-HIAA) (Shintani et al., 1993).

These reports suggest that IL- 1 plays a role in stress-induced central responses including both activation of the HPA axis and elevated monoamine release. In fact, it has been suggested that the physiological and behavioral changes caused by restraint stress can be mimicked by the administration of IL-1 (Dunn et al., 1991). A recent study showed that IL-1 $\beta$ mRNA in the rat hypothalamus is induced by acute immobilization stress (IS) during periods ranging from 60 to $120 \mathrm{~min}$ (Minami et al., 1991).

However, it has not been clarified whether biologically active IL- 1 is generated in the brain by IS, or whether IL- 1 is essential for inducing such acute stress responses. In order to assess this possibility, we examined whether acute IS enhances the levels of IL-1 activity in the rat hypothalamus. In addition, to examine the role of hypothalamic IL-1 in IS-induced neurohormonal changes, we designed experiments involving the administration of interleukin- 1 receptor antagonist (IL-1 Ra) directly into the rat anterior hypothalamus. IL-1 Ra is known to have the same molecular size as mature interleukin-1, and to competitively block the type I IL-1 receptor (Dinarello et al., 1981; Seckinger and Dayer, 1987; Eisenberg et al., 1990; Dinarello, 1991; Dinarello and Wolff, 1993). We therefore investigated whether elevated monoamine release in the rat hypothalamus and increased plasma adrenocorticotropic hormone (ACTH), in response to IS, are inhibited by IL-1Ra. Moreover, we administered IL-1Ra at different times in this nodel to detect at which time points IL-1 was exerting its effects. 


\section{Materials and Methods}

Materials. IL-1Ra (endotoxin levels below $100 \mathrm{fg} / \mathrm{ng}$ of IL-1Ra) was kindly provided by Dr. Robert C. Thompson of Synergen, Inc. (Boulder $\mathrm{CO}$ ). Bioactivity of IL-1Ra is shown in a previous report (Wakabayashi et al, 1991). Other materials were obtained from the following sources; hrIL-1 $\beta$ (one unit is equivalent to $2 \mathrm{pg}$; endotoxin levels below $100 \mathrm{fg} /$ ng of IL-1 $\beta$ ), Endogen (Boston, MA); RPMI-1640, GIBCO (Grand Island, NY); fetal calf serum, Mitsubishi-Kasei (Tokyo, Japan); bovine serum albumin, concanavalin A, Sigma Chemical Co. (St Louis, MO): $0.45 \mu \mathrm{m}$ membrane, Micron Separations Inc. (Westboro, MA); 96-well culture plate, Costar; homogenization tube, Takashima Shoten (Tokyo, Japan); microdialysis probe, dual-pranger pump (EP-10), electrochemical detector with a carbon-graphite electrode (ECD-100), CA-5ODS column (150 mm $\times 4.6 \mathrm{~mm}$ i.d), MA-ODS $(250 \mathrm{~mm} \times 4.6 \mathrm{~mm}$ i.d., Eicom (Kyoto, Japan); integrator (chromatocorder 12) JASCO (Tokyo, Japan); auto-sampling injector (231-401) Gilson Medical Electronics Inc. (Middleton, WI); sodium 1-octanesulfonate, ethylenediamine tetraacetic acid $2 \mathrm{Na}$, Nacalai tesque (Kyoto, Japan).

Animals. Seven-week-old male Sprague-Dawley rats and 4-week-old male $\mathrm{C} 3 \mathrm{H} / \mathrm{HeJ}$ mice were housed in a temperature-controlled room (23$25^{\circ} \mathrm{C}$ ) under a $12 \mathrm{hr}$ reversed light-dark schedule for 1-2 weeks. Food and water were provided ad libitum at all times. Eight- or nine-weekold rats and 5- or 6-week-old mice were used for the experiments. The experiments conform to the standards put forth in the Handbook for the Use of Animals In Neuroscience Research.

Immobilization stress. In experiments designed to measure the levels of hypothalamic IL-1, rats were immobilized by placing them in plastic restrainers $(6 \times 6 \mathrm{~cm}$ internal scale). In a series of experiments aimed at determining the levels of hypothalamic monoamines and plasma ACTH, rats were immobilized by taping their paws because of technical difficulties in handling the animals with the use of plastic restrainers. In order to avoid circadian rhythm problems, only 4-8 rats were immobilized each day during a fixed time period, from 10:00 to 12:00.

$I L-I$ assay. After the rats had been subjected to the IS for designated periods, they were lightly anesthetized with diethyl ether, and the hypothalamus was dissected stereotaxically by cutting the brain on icechilled sterilized glass boards, at the optic chiasma rostrally, at $2.5 \mathrm{~mm}$ from the midline laterally, at $3 \mathrm{~mm}$ from the optic chiasma caudally, and at $2.5 \mathrm{~mm}$ from the base of the brain dorsally. Cubic blocks of the hypothalamus were immediately put into $250 \mu \mathrm{l}$ of RPMI $1640-$ containing homogenization tubes, and gently homogenized in ice. Each tube was centrifuged $\left(10,000 \times g, 10 \mathrm{~min}, 4^{\circ} \mathrm{C}\right)$, and the supernatant was aliquotted into plastic tubes. These samples were stored in liquid nitrogen until IL-1 measurement.

Thymocyte-proliferating activity was taken as an index of IL-1 activity in the hypothalamus. Cell suspensions of thymocytes were prepared by gently slacking the thymus from $5-6$-week-old $\mathrm{C} 3 \mathrm{H} / \mathrm{HeJ}$ male mice. The cells were washed three times with RPMI 1640 supplemented with $10 \% \mathrm{FCS}, 5 \times 10^{-5} \mathrm{M}$ 2-mercaptoethanol, and antibiotics after hemolysis with a mixed solution consisting of one volume of $0.083 \mathrm{~N}$ $\mathrm{NH}_{4} \mathrm{Cl}$ solution and nine volumes of Tris $\mathrm{HCl}$ buffer (pH 7.65). After the cells had been resuspended at a density of $5 \times 10^{6}$ cells $/ \mathrm{ml}$, half were preincubated at $37^{\circ} \mathrm{C}$ with $5 \mu \mathrm{g} / \mathrm{ml}$ of IL-1Ra to block IL-1 receptors for $2 \mathrm{hr}$. The cells were cultured in 96-well culture plates for $72 \mathrm{hr}$. The contents of each well consisted of $100 \mu \mathrm{l}$ of thymocytesuspended culture medium in the presence or absence of $5 \mu \mathrm{g} / \mathrm{ml}$ of IL-1 Ra, $50 \mu \mathrm{l}$ of culture medium in the presence or absence of $0.2 \mu \mathrm{g}$ of concanavalin A, and $50 \mu \mathrm{l}$ of sample. Samples were added in duplicate. Cells were labeled with ${ }^{3} \mathrm{H}$-thymidine for the final $6 \mathrm{hr}$ of incubation. The cells were then washed and harvested onto glass fiber discs using a semiautomatic cell harvester. ${ }^{3} \mathrm{H}$-thymidine incorporated into the cells was determined using a xylene-based liquid scintillator on a $\beta$-counter. The mean counts per minute $(\mathrm{cpm})$ of the samples were compared to the responses obtained with a calibration curve $(0,1,10$, $10^{2}, 10^{3}$, and $10^{4} \mathrm{pg} / \mathrm{ml}$ ) using hrIL-1 $\beta$ as the standard.

In the presence of $1 \mu \mathrm{g} / \mathrm{ml}$ of concanavalin $A$, hrIL- $1 \beta$ stimulated proliferation of thymocytes in a dose-dependent manner, while the IL1 Ra pretreatment significantly inhibited cell proliferation (Fig. 1A). We considered the values, which were obtained by subtracting the ${ }^{3} \mathrm{H}$-thymidine incorporation levels in wells containing IL-1Ra from the levels in wells without IL-1Ra, to represent pure proliferation effects duc to the hrIL-1 $\beta$. Figure $1 B$ presents the relationship between hrIL-1 $\beta$ concentrations and the subtracted values of ${ }^{3} \mathrm{H}$-thymidine incorporation. The levels of IL-1 activity in the hypothalamus were determined using this standard curve, and expressed as the equivalent of hrIL-1 $\beta$-induced
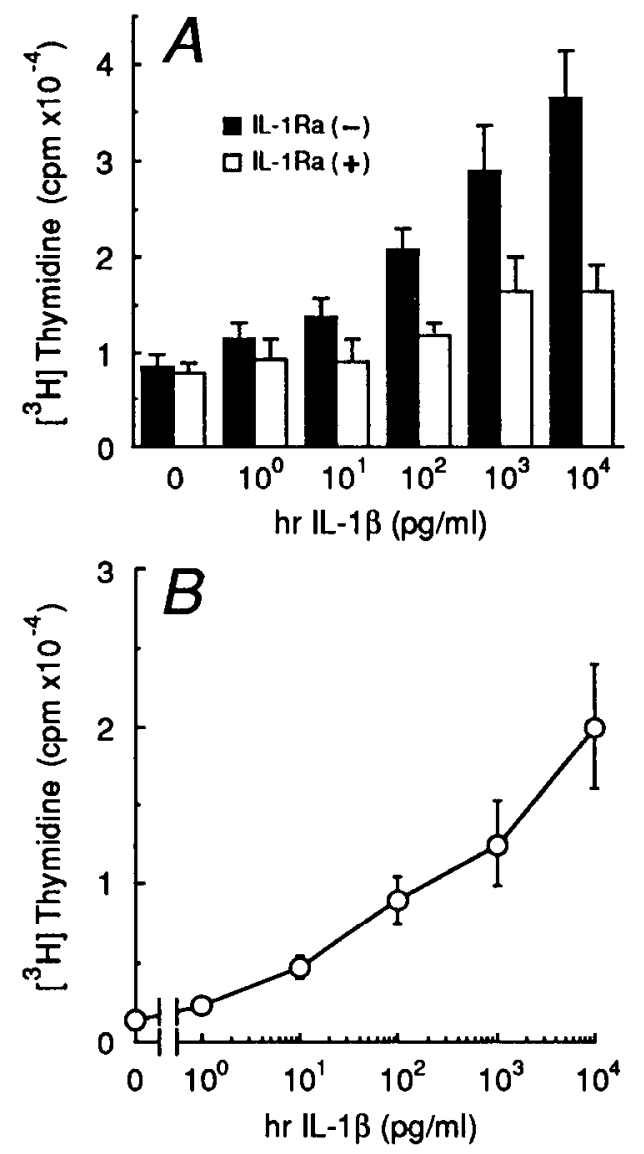

Figure 1. A, Relation between the incorporated levels of " $\mathrm{H}$-thymidne and the hrIL-1 $\beta$ concentration in thymocytes used for cytokine bioassay. Thymocytes, which had been treated with $5 \mu \mathrm{g} / \mathrm{ml}$ of IL-1Ra (open bar) or vehicle (solid bar), were cultured in the presence of both $1 \mu \mathrm{g} /$ $\mathrm{ml}$ concanavalin $\mathrm{A}$ and several concentrations of hrIL-1 $\beta$. The incorporation into the cells without concanavalin $A$ treatment was in the range of $200-300 \mathrm{cpm}$. The proliferation of thymocytes treated with IL-1Ra was significantly inhibited $(P<0.05, n=12-36)$. $B$, Relationship between the hrIL-1 $\beta$ concentrations and values obtained by sub tracting the levels of ${ }^{3} \mathrm{H}$-thymidine incorporated into concanavalin $\mathrm{A}-$ stimulated cells in wells containing IL-1Ra from the levels in wells without IL-1Ra. The lower limit of detection for this assay was in the $8-12 \mathrm{pg} / \mathrm{ml}$ range. Circles and vertical bars represent means and SEM, respectively. Circles without bars indicate that the size of the circle is greater than the length of the bar.

proliferation activity. The lower limit of detection for this assay was in the $8-12 \mathrm{pg} / \mathrm{ml}$ range.

Microdialysis. In order to administer agents directly into the hypothalamus where a microdialysis probe had been inserted, we used a microdialysis probe equipped with a microinjection tube (Shintani et al., 1993). In order to facilitate estimation of differences in IS-induced monoamine responses between IL-1Ra-treated and vehicle-treated sides of the anterior hypothalamus in the same rat, two guide shafts were placed in the bilateral anterior hypothalami. Surgery was performed using a previously described method (Shintani et al., 1993). Rats were anesthetized with an intraperitoneal injection of pentobarbital $(30 \mathrm{mg} /$ $\mathrm{kg}$ ), and guide shafts were stereotaxically implanted in the left- and right-anterior hypothalami $(1.5 \mathrm{~mm}$ posterior to the bregma, $4.5 \mathrm{~mm}$ lateral to the midline, $7.0 \mathrm{~mm}$ below the skull surface, at $25^{\circ}$ of inclination for the vertical line, according to the atlas of Paxinos and Watson; Fig. 2A). After the series of experiments had been completed, each probe position was histologically confirmed by a previously described method (Shiozawa et al., 1989) (Fig. 2B). In brief, the rat was perfused with periodate-lysine-paraformaldehyde under anesthesia with diethyl ether, and the dissected brain was fixed overnight at $4^{\circ} \mathrm{C}$ in periodatelysine-paraformaldehyde. After the tissue had been dehydrated in an 

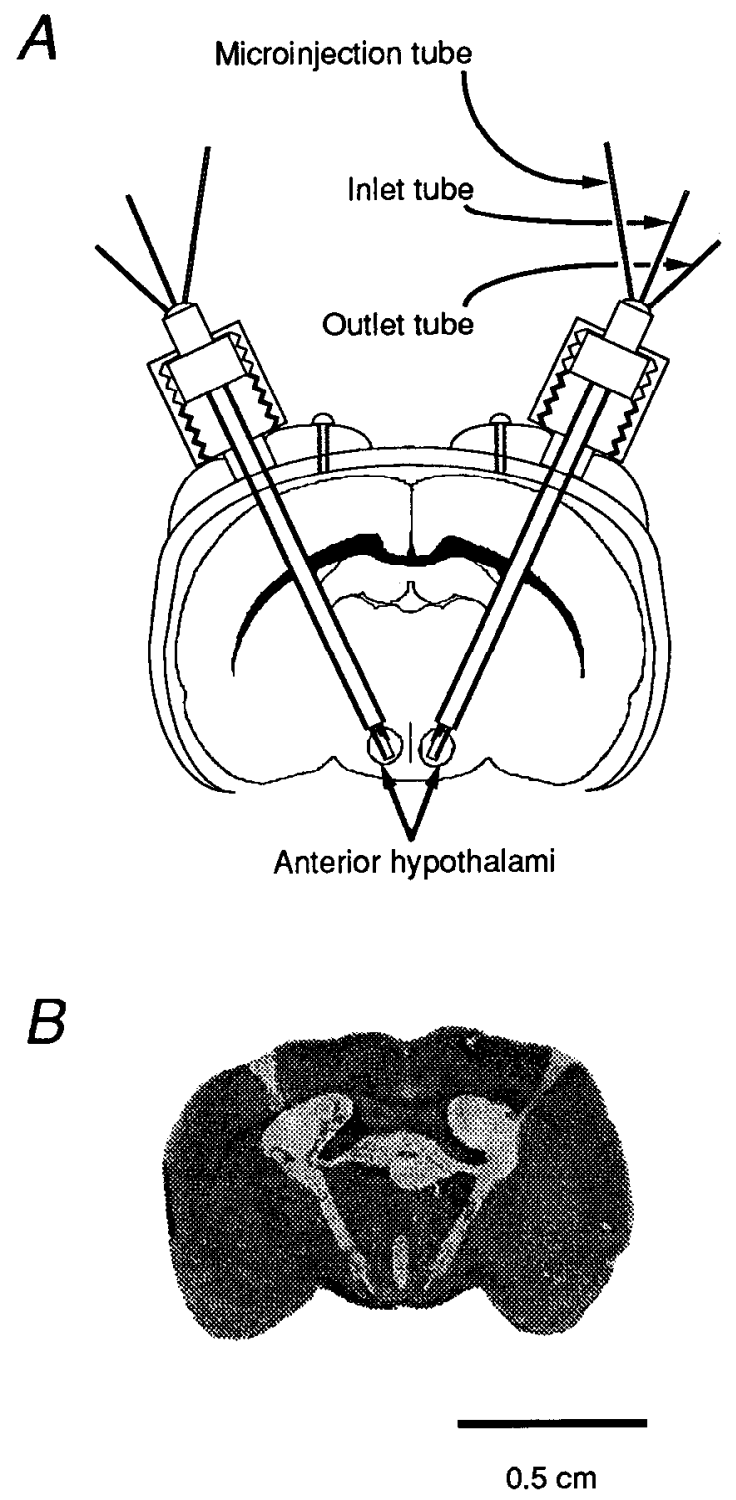

Figure 2. Schema $(A)$ and conteal slice $(B)$ showing inplantation of a microdialysis probe equipped with a microinjection tube into both sides of the anterior hypothalami. Rat brain was perfused with periodate-lysine-paraformaldehyde, followed by dissection. After the tissue had been embedded in paraffin, it was sliced at a $10 \mu \mathrm{m}$ thickness and stained with hematoxylin and eosin. The bar indicates a length of 0.5 $\mathrm{cm}$.

ascending series of alcohols, cleared in xylene, and embedded in paraffin, the sections were sliced at a $10 \mu \mathrm{m}$ thickness and stained with hematoxylin and eosin. Animals in which the probes were incorrectly located were excluded from the analysis.

To allow adequate recovery time following surgery, rats were housed under the same conditions for 7-10 d. On the day before microdialysis was started, the microdialysis probe had been inserted through the guide shaft into the anterior hypothalamus. The probe was filled with 0.45 $\mu \mathrm{m}$ membrane-filtered and degassed Hanks' solution $(137 \mathrm{mM} \mathrm{NaCl}$, $5.4 \mathrm{mM} \mathrm{KCl}, 1.3 \mathrm{mM} \mathrm{CaCl}, 0.8 \mathrm{~mm} \mathrm{MgSO}{ }_{4}, 0.338 \mathrm{mM} \mathrm{Na} \mathrm{HPO}_{4}, 0.4$ $\mathrm{mM} \mathrm{KH}_{2} \mathrm{PO}_{4}, 5.6 \mathrm{~mm}$ glucose, $4.2 \mathrm{~mm} \mathrm{NaHCO}$, $\mathrm{pH} 7.4$ ). Each rat was subsequently housed in an individual plastic cage, where the experiment was to be performed, to allow habituation to the setting for several hours. The Hanks' solution was then perfused through the probe at a velocity of $3 \mu \mathrm{l} / \mathrm{min}$, and the dialysate was collected at $20 \mathrm{~min}$ intervals for more than $2 \mathrm{hr}$ by a previously described method (Shintani et al., 1993).

At $60 \mathrm{~min}$ before the start of IS, IL-1Ra or vehicle was administered directly into each side of the anterior hypothalamus. The administered dose of IL-1Ra was $2 \mu \mathrm{g}$ dissolved in $2 \mu \mathrm{l}$ of sterile Hanks' solution containing $0.1 \%$ BSA as a carrier protein. IL-1 Ra was administered through the microinjection tube into one side of the anterior hypothalamus, or the same volume of vehicle was administered simultaneously to the contralateral side in the same rat. Administration was performed at a rate of $0.4 \mu \mathrm{l} / \mathrm{min}$ using a microinjection pump. IS was then performed without stopping the aforementioned sampling, and was continued for up to $6 \mathrm{hr}$. Each sample was immediately injected into an HPLC system.

In another series of experiments, IL-1Ra or vehicle was administered at $5 \mathrm{~min}$ before, or at 5 and $60 \mathrm{~min}$ after, the start of IS, and the levels of NE in the dialysate were determined using the HPLC system.

We excluded some data according to the criteria described below. Animals with basal levels of monoamines, in any experiment, twofold higher than the mean levels constituted less than $5 \%$ of the rats used and were excluded from further analysis. In addition, animals with basal levels below $50 \%$ of mean levels constituted less than $5 \%$ of the rats used and were also excluded. Moreover, the validity of the system was assessed by the depolarizing effect of $60 \mathrm{mM} \mathrm{KCl}$ on monoamine release at the end of each experiment. Animals failing to respond to this test accounted for less than $20 \%$ of the rats used and were excluded from the analysis. The levels of monoamines were measured on both sides of the anterior hypothalami, and animals with significantly different basal releases on the left and the right side comprised less than $10 \%$ of the rats used. These animals were also excluded from further analysis.

HPLC analysis. The levels of NE, DA, 5-HT, MHPG, DOPAC, HVA, and 5-HIAA in the dialysate were determined using an HPLC system as described previously (Shintani et al., 1993). The limit of detection was $0.5-1 \mathrm{pg} / 100 \mu \mathrm{l}$.

ACTH assay. In experiments involving measurement of plasma ACTH levels, polyethylene tubing for collecting blood was inserted into the jugular vein under pentobarbital $(30 \mathrm{mg} / \mathrm{kg}$ ) anesthesia administered by intraperitoneal injection, as described previously (Nakaki et al., 1981). In order to administer agents directly into the bilateral hypothalami, 26 gauge needles were inserted into the bilateral anterior hypothalami by a previously described method (Shintani et al., 1993), following insertion of the polyethylene tubing.

At $60 \mathrm{~min}$ before the initiation of IS, $1 \mathrm{ml}$ of blood was collected through the polyethylene tubing from the jugular vein, while the rats were conscious but resting, on the day of the experiment. The blood was immediately placed in an ice-chilled, EDTA-containing glass tube. Each glass tube containing blood was gently shaken and centrifuged $\left(3,000 \mathrm{rpm}, 10 \mathrm{~min}, 4^{\circ} \mathrm{C}\right)$, and plasma was transferred to a plastic tube and stored at $-20^{\circ} \mathrm{C}$ for subsequent determination of plasma ACTH levels by previously described methods (Shintani et al., 1993). Immediately before the start of IS, $1 \mathrm{ml}$ of blood had been collected again, followed by the subsequent collection of $1 \mathrm{ml}$ of blood at $30,60,120$, 240 , and $360 \mathrm{~min}$. The sedimented blood cells were resuspended with the same volume of sterile saline, and reinjected into the rats after each blood sampling. IL-1 Ra was administered directly into both sides of the anterior hypothalami through 26 gauge needles at a velocity of $0.4 \mu \mathrm{l} /$ min using the microinjection pump. The administered dose of IL-1Ra was 2 or $20 \mu \mathrm{g}$ dissolved in $2 \mu \mathrm{l}$ of sterile Hanks' solution containing $0.1 \% \mathrm{BSA}$ as a carrier protein. Vehicle was administered to other rats in a manner similar to that used for IL-1Ra. Administration of IL-1Ra or vehicle was performed at scveral points, and a detailed description of the timing is given in the figure legends.

Data analysis. Results are presented as means \pm SEM. Data were analyzed statistically using ANOVA. A $p<0.05$ was considered significant.

\section{Results}

\section{Effects of IS on levels of IL-1 activity in the hypothalamus}

After the start of IS, the levels of IL-1 activity in the hypothalamus reached a maximum at $60 \mathrm{~min}$, and remained significantly increased at $240 \mathrm{~min}$ (Fig. 3). The IL-1 activity gradually decreased thereafter, and returned to the pre-IS levels at $360 \mathrm{~min}$ despite the continuance of IS. 


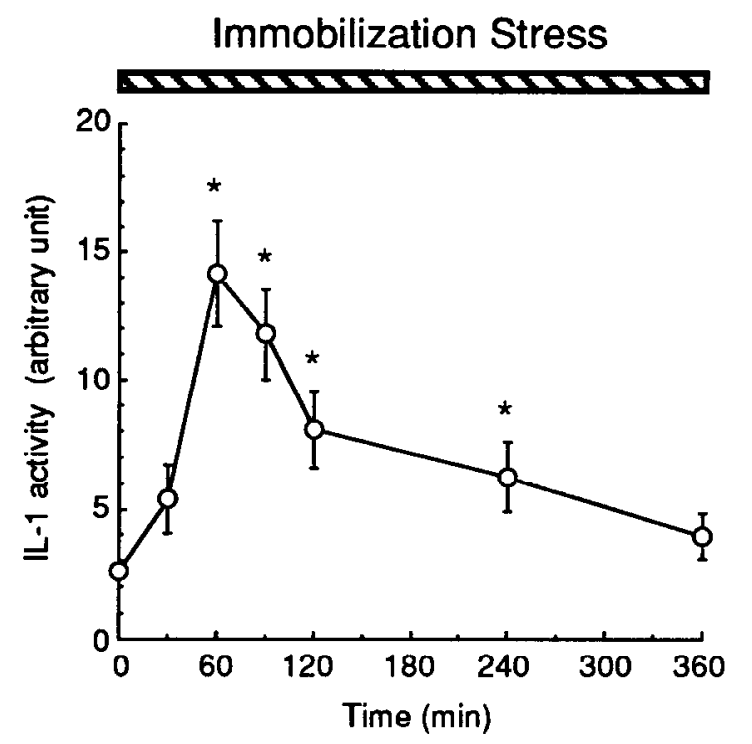

Figure 3. IL-1 levels in rat hypothalami during IS. Rats were immobilized for periods of $30 \mathrm{~min}$ to $360 \mathrm{~min}$ by placing them in plastic restrainers. The IL-1 levels in the supernatants of homogenates of the dissected rat hypothalami were determined using the standard curve shown in Figure $1 B$. One arbitrary unit on the ordinate is equivalent to $1 \mathrm{pg}$ hrlL-1 $\beta$ per $1 \mathrm{mg}$ wet hypothalamic weight. For explanations of circles and vertical bars, see Figure 1 legend. IL-1 activity was $2.4 \pm$ $0.3 \mathrm{pg} / \mathrm{mg}$ wet hypothalamic weight in the preimmobilized rat. $* P<$ 0.05 versus zero time.

Effects of IL-IRa on the IS-induced increase in monoamine levels in the hypothalamus

We examined whether directly administered doses of IL-1Ra were sufficient to inhibit the effects of IL-1 using a previously described microdialysis method (Shintani et al., 1993). We confirmed that $2 \mu \mathrm{g}$ of IL-1Ra was capable of inhibiting increases in the levels of $\mathrm{NE}$ caused by $1 \mathrm{ng}$ of hrIL-1ß, when IL-1Ra had been preadministered directly into the anterior hypothalamus through the microinjection tube $60 \mathrm{~min}$ before the hrIL-1 $\beta$ was administered directly into the same region (Fig. 4). Administration of IL-1Ra alone did not appear to change the basal release of NE in the anterior hypothalamus significantly (data not shown).

In order to assess the involvement of IL-1 in IS-induced monoamine release responses, we determined the levels of $\mathrm{NE}$, DA, 5-HT, and their metabolites in dialysate perfusing the IL1Ra-treated side of the anterior hypothalamus and the contralateral vehicle-treated side of the anterior hypothalamus in an immobilized rat. On the side treated with vehicle, the levels of NE and DA increased and reached maxima, which were about three times higher than the basal levels, at $60 \mathrm{~min}$ after the start of IS and then gradually decreased to the baseline concentrations despite the continuance of IS (Fig. $5 A, E$ ). On the other hand, the 5-HT levels immediately increased and reached a maximum about four times higher than the basal level during the initial 20 min of IS, and rapidly decreased thereafter and had reached levels only 1.5 times the baseline by $100 \mathrm{~min}$ (Fig. $5 \mathrm{C}$ ). The levels of MHPG, a metabolite of NE, also increased after the start of IS, and remained 3-4 times higher than baseline until 180 min after the start of IS, then gradually returned to baseline (Fig. $5 B$ ). The levels of 5-HIAA, a metabolite of 5-HT, gradually increased to about two times higher than baseline and continued to increase for the duration of the stress (Fig. 5D). The levels

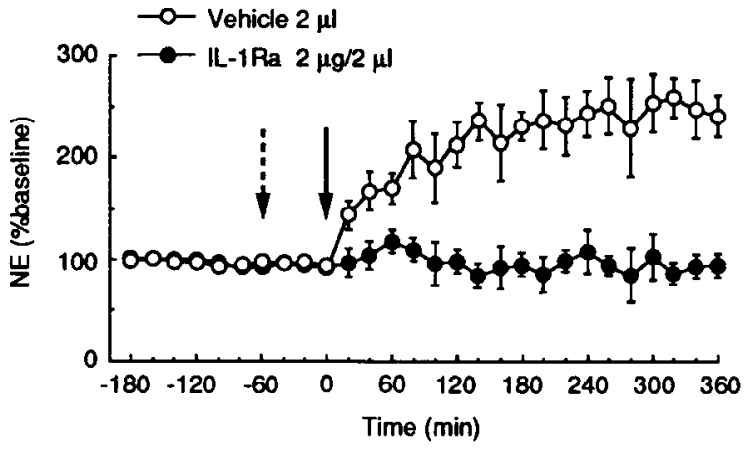

Figure 4. Effects of IL-1Ra on the hrIL-1 $\beta$-induced hypothalamic NE levels. IL-1Ra was administered directly into the hypothalamus at 60 min prior to injection of hrIL-1 $\beta$. Broken arrow represents the timing of IL-1Ra $(2 \mu \mathrm{g} / 2 \mu \mathrm{l} ; 0)$ or vehicle $(\mathrm{O})$ injection. Solid arrow represents the timing of $\mathrm{hrLL}-1 \beta(1 \mathrm{ng} / \mu \mathrm{l})$ injection. For explanations of circles and vertical bars, see Figure 1 legend. The $100 \%$ value of NE is $2.21 \pm 0.11(\mathrm{pg} / 20 \mathrm{~min}$ defined as the mean \pm SEM of eight samples). $\bigcirc$ versus $P<0.05, n=8$.

of DOPAC and HVA, metabolites of DA, increased and reached a maximum at $100 \mathrm{~min}$ after the start of IS and then gradually decreased (Fig. $5 F, G$ ).

In the side treated with $2 \mu \mathrm{g}$ of IL-1Ra at $60 \mathrm{~min}$ prior to IS, the IS-induced increases in the aforementioned monoamine levels were significantly inhibited. Significant inhibition of increases in the levels of NE, 5-HT, and DA was observed during the period from $0 \mathrm{~min}$ to $360 \mathrm{~min}, 0 \mathrm{~min}$ to $60 \mathrm{~min}$, and $0 \mathrm{~min}$ to $240 \mathrm{~min}$, respectively, of IS (Fig. $5 A, C, E$ ). Elevations of their metabolites, MHPG, 5-HIAA, DOPAC, and HV $\Lambda$, were also inhibited significantly from $60 \mathrm{~min}$ to $360 \mathrm{~min}, 80 \mathrm{~min}$ to 360 $\mathrm{min}, 40 \mathrm{~min}$ to $240 \mathrm{~min}$, and $60 \mathrm{~min}$ to $180 \mathrm{~min}$, respectively, after the start of IS (Fig. $5 B, D, F, G$ ). Despite the treatment with IL-1Ra, significant increases in the levels of monoamines other than 5-HIAA were observed in comparison to the baseline levels during the early period of IS (Fig. $5 A-G$ ).

In order to compare the responses of the left and right sides of the anterior hypothalamus to equal stimulation, the same amounts of IL-1 Ra were administered directly into the opposite side of the anterior hypothalamus. We found no difference in responses between the left and right sides under conditions in which IL-1Ra had been injected (data not shown).

In order to assess the importance of timing on IL-1Ra effects, the same amounts of IL-1 Ra were administered directly into the anterior hypothalamus at several points, and the levels of NE in the dialysate perfusing the treated region were determined. $\Lambda$ significant inhibitory effect of IL-1Ra on increased NE levels was still observed when IL-1Ra, in the same amount, was administered directly into the anterior hypothalamus at $5 \mathrm{~min}$ before the start of IS (Fig. 6A). However, when the same amount of IL-IRa was administered at $5 \mathrm{~min}$ (Fig. $6 \mathrm{~B}$ ) or $60 \mathrm{~min}$ (Fig. $6 C$ ) after the start of IS, IL-1Ra did not inhibit the IS-induced elevation of hypothalamic NE levels.

\section{Effects of IL-1Ra on IS-induced elevation of plasma ACTH levels}

We examined whether preadministration of IL-1Ra inhibited ISinduced elevation of plasma ACTH levels. The basal plasma levels of ACTH were $48 \pm 8 \mathrm{pg} / \mathrm{ml}(n=80)$. Before IS was started, no significant changes in basal plasma ACTH due to blood sampling or replacement were observed (Fig. 7C,D). 


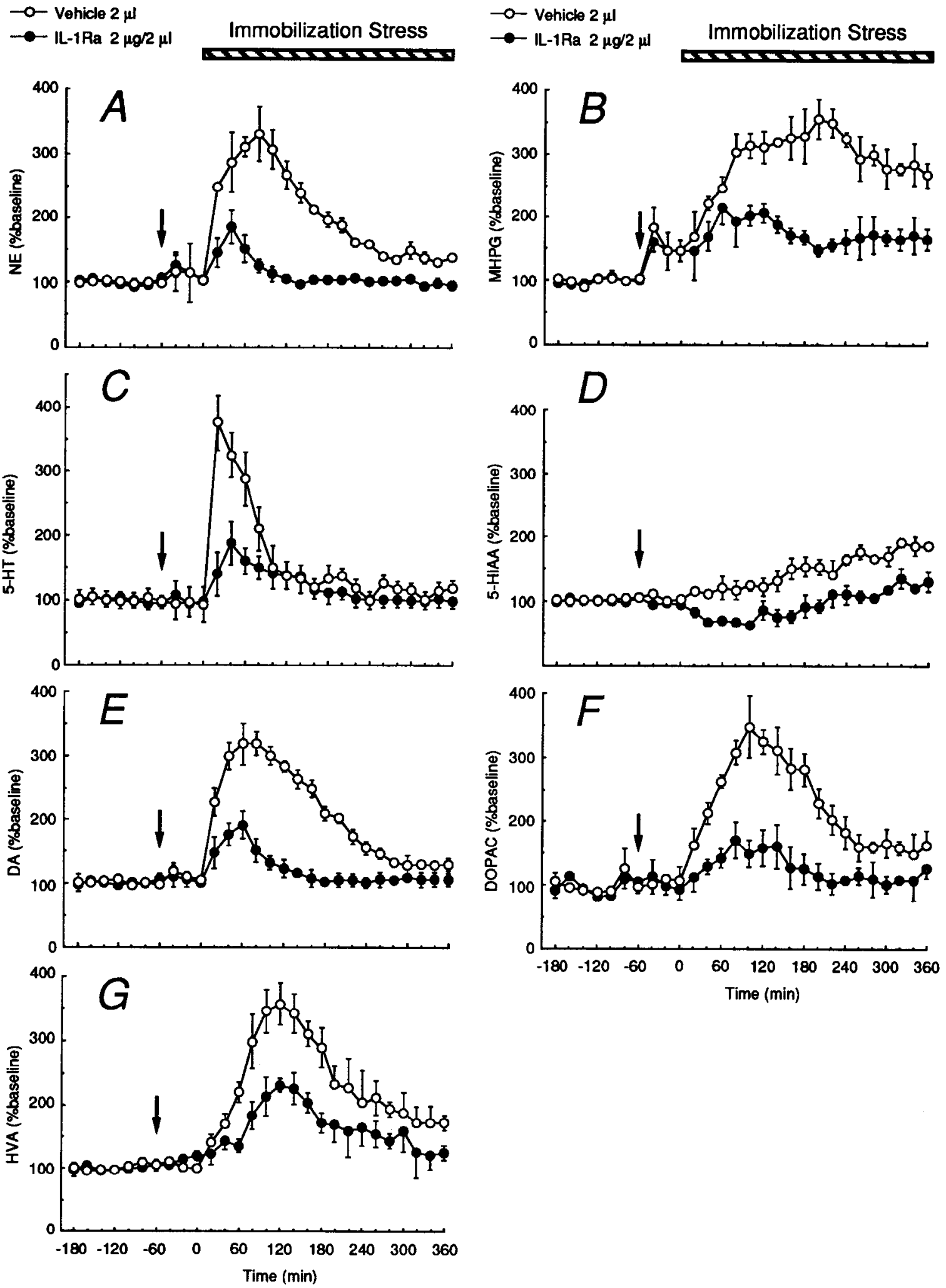

Figure 5. Effects of IL-1Ra administered into the rat anterior hypothalamus through a microinjection tube on hypothalamic levels of $(A)$ NE, $(B)$ MHPG, $(C)$ 5-HT, $(D)$ 5-HTAA, $(E)$ DA, $(F)$ DOPAC, and $(G)$ HVA in response to IS. Arrows represent the timing of IL-1Ra administration (2 $\mu \mathrm{g} / 2 \mu \mathrm{l} ; \mathrm{O})$ and vehicle $(\bigcirc)$ simultaneously administered into the contralateral side. Horizontal hatched bars represent the periods of IS. For explanations of circles and vertical bars, see Figure 1 legend. One hundred percent values of the amines and metabolites are, for NE, $2.13 \pm 0.21$; MHPG, $16.83 \pm 0.55 ; 5-\mathrm{HT}, 3.35 \pm 0.22 ; 5-\mathrm{HI} \Lambda \Lambda, 366.2 \pm 4.0 ; \mathrm{DA}, 1.34 \pm 0.21$; DOPAC, $127.4 \pm 2.1$; and HVA, $80.4 \pm 1.0(\mathrm{pg} / 20 \mathrm{~min}$ defined as the mean \pm SEM of eight samples). $\bigcirc$ versus $P<0.05, n=8$. 

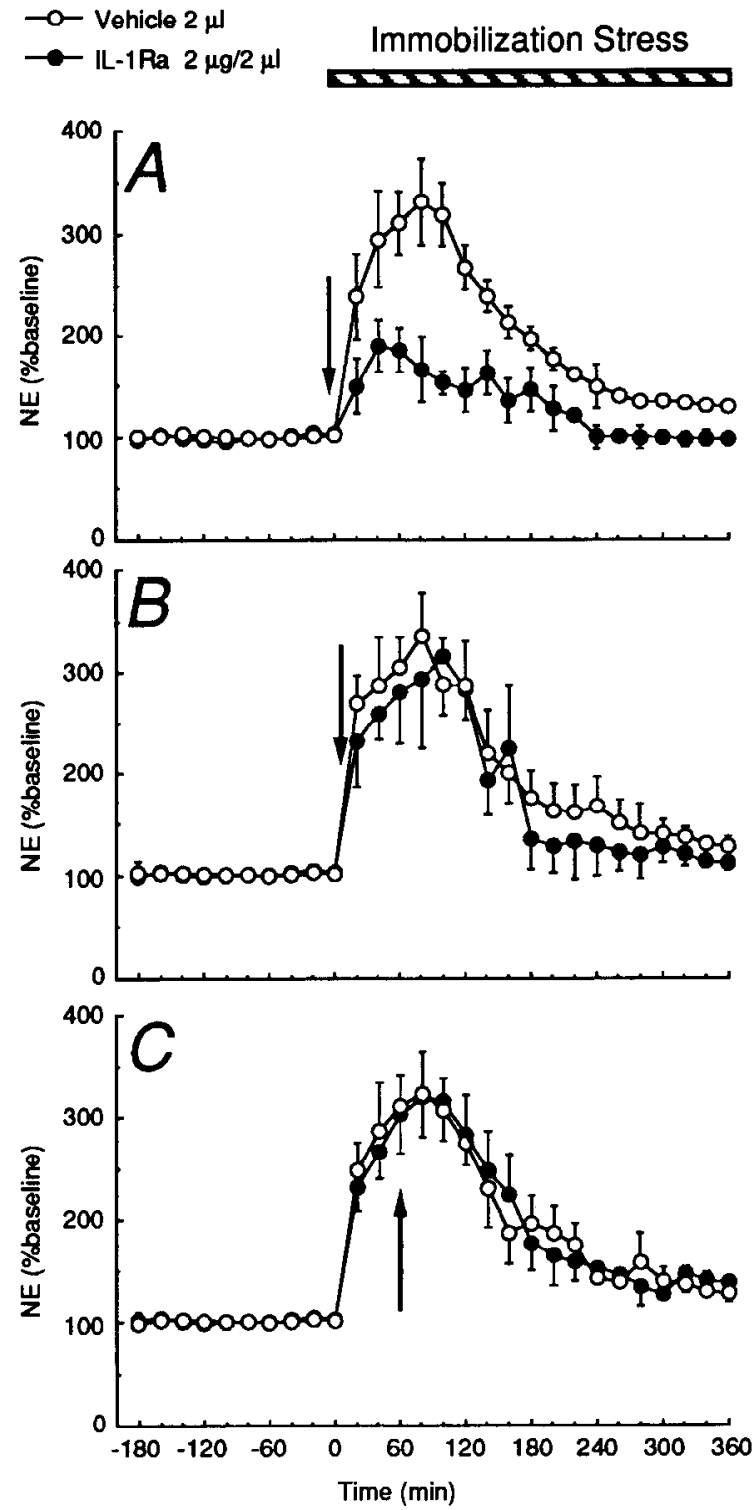

Figure 6. Effects on hypothalamic NE levels of the timing of IL-1Ra administration. IL-1Ra was administered directly into one side of the rat anterior hypothalamus through a microinjection tube $5 \mathrm{~min}$ before starting IS $(A)$, or at $5 \mathrm{~min}(B)$ and $60 \mathrm{~min}(C)$ after starting the IS, and vehicle was simultaneously administered into the contralateral side. Arrows represent the timing of $\mathrm{IL}-1 \mathrm{Ra}(2 \mu \mathrm{g} / 2 \mu \mathrm{l}$; ) or vehicle $(2 \mu \mathrm{l}$; O) administration. Horizontal hatched bars represent the period of IS exposure. For explanations of circles and vertical bars, see Figure 1 legend. One hundred percent NE values were $(A) 2.43 \pm 0.18,(B) 2.47$ \pm 0.13 , and $(C) 2.44 \pm 0.14(\mathrm{pg} / 20 \mathrm{~min}$ defined as the mean $\pm \mathrm{SEM}$ of eight samples). $\bigcirc$ versus $P<0.05, n=8$.

When vehicle was administered directly into the bilateral anterior hypothalami, the plasma ACTH levels increased slightly just in response to the manipulation necessary for administration (Fig. $7 A, B$ ). After the start of IS, the plasma ACTH levels significantly increased peaking at a level about 20 times higher than the basal levels, and thereafter rapidly decreased, reaching baseline by $360 \mathrm{~min}$. When $2 \mu \mathrm{g}$ of IL-1Ra was administered directly into the bilateral anterior hypothalami at $60 \mathrm{~min}$ before the start of IS, the IS-induced elevation of plasma ACTH levels was significantly inhibited during the period from $30 \mathrm{~min}$ to 120 $\min$ (Fig. 7A). When $20 \mu \mathrm{g}$ of IL-1Ra was administered at 60
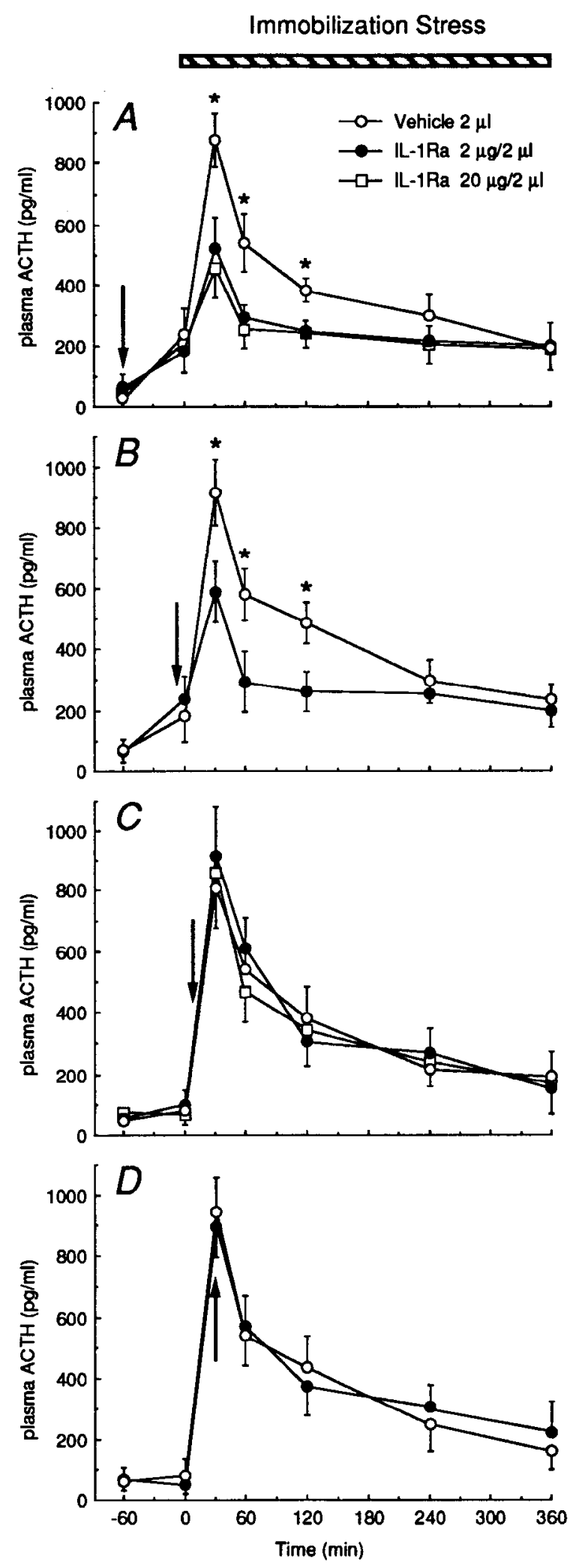

Figure 7. Effects of IL-1Ra on plasma levels of ACTH in response to IS. IL-1Ra or vehicle was administered directly into the anterior hypothalami at $60 \mathrm{~min}(A)$ and $5 \mathrm{~min}(B)$ before starting IS, or at $5 \mathrm{~min}$ $(C)$ and $30 \mathrm{~min}(D)$ after initiating IS exposure. Arrows represent the timing of IL-1Ra $(2 \mu \mathrm{g} / 2 \mu \mathrm{l}, \mathrm{O} ; 20 \mu \mathrm{g} / 2 \mu \mathrm{l}, \square)$ or vehicle $(2 \mu \mathrm{l}, \mathrm{O})$ injection. Horizontal hatched bars represent the period of IS exposure. For cxplanations of circles and vertical bars, see Figure 1 legend. $* 0$ versus $P<0.05, n=8$. 
min before the start of IS, the same significant inhibition as that produced by $2 \mu \mathrm{g}$ of IL-1Ra was observed (Fig. 7A). Two micrograms of IL-1Ra apparently elicited a maximal inhibitory effect on IS-induced ACTH secretion, since $2 \mu \mathrm{g}$ of IL-1Ra did not elicit weaker inhibitory effects than $20 \mu \mathrm{g}$ of the antagonist. We also examined the importance of the timing of the IL-1Ra effect on IS-induced increases in plasma ACTH levels. The significant inhibitory effect of IL-1Ra on the increase in plasma ACTH was unchanged in animals to which $2 \mu \mathrm{g}$ of IL-1Ra had been administered at $5 \mathrm{~min}$ before the start of IS (Fig. $7 B$ ). However, when the same amount of IL-1Ra was administered at $5 \mathrm{~min}$ or $30 \mathrm{~min}$ after the start of IS, IL-1Ra did not exert significant inhibitory effects (Fig. $7 C, D$ ). Moreover, when a large dose of IL-1Ra $(20 \mu \mathrm{g})$ was administered at $5 \mathrm{~min}$ after the start of IS, no significant inhibitory effects were observed (Fig. 7C).

\section{Discussion}

In the present study, we found that IS enhanced the levels of IL-1 bioactivity in the rat hypothalamus, and that the IS-induced increases in hypothalamic monoamines and plasma ACTH were inhibited by pretreatment with IL-1Ra. In addition, inhibitory effects of IL-1Ra were observed when IL-1Ra had been administered immediately before the start of IS, but not immediately after the IS.

Using a microdialysis technique, we previously demonstrated that $1 \mathrm{ng}$ of hrIL-1 $\beta$, administered directly into the rat anterior hypothalamus, increased the levels of NE, DA, 5-HT, and their metabolites in the anterior hypothalamus (Shintani et al., 1993). On the other hand, it has been shown that IL-1 effects on the hypothalamus include increased secretion of CRH (Berkenbosch et al., 1987; Sapolsky et al., 1987) and activation of the HPA axis (Barbanel et al., 1990; Besedovsky et al., 1991). In light of our previous findings and those of other investigators, we proposed that both the elevation of monoamine release and activation of the HPA axis, which are induced by a stress load such as IS, are due to the effects of hypothalamic IL-1 (Shintani et al., 1993).

There are some reports indicating that glial cells produce IL-1 (Giulian and Tapscott, 1988). On the other hand, IL-1 $\beta$ immunoreactivity has been reported within neuronal fibers of the human brain (Breder et al., 1988). Recent reports have shown that IL- 1 is present in neurons in the normal rat brain (Lechan et al., 1990). However, no essential role of IL-1 in neurons has been demonstrated (Dinarello and Wolff, 1993). Our results also suggest that IL-1 is detectable in the normal brain (Fig. 3). Whether or not IL-1 is able to cross the blood-brain barrier is controversial (Dinarello, 1991; Rothwell, 1991; Banks and Kastin, 1992). The circulating concentrations of biologically active IL- 1 are usually low ( $<40 \mathrm{pg} / \mathrm{ml}$ ) (Dinarello and Wolff, 1993), even during the acute phase inflammatory response $(<300 \mathrm{pg} / \mathrm{ml})$ (Rothwell, 1991). Since our data show that the basal level of IL-1 in the hypothalamus is about $2 \mathrm{pg} / \mathrm{mg}$ wet hypothalamus (approximate $2 \mathrm{ng} / \mathrm{ml}$ ) and that the concentration is 100 -fold higher than that of plasma, it seems unlikely that accumulation of peripheral IL-1, if any, can reach such a high concentration in the hypothalamus. Therefore, it is more likely that hypothalamic IL-1 originates from the central nervous systems. However, because we determined the IL-1 activity in tissue homogenates, it is unclear whether the detected IL-1 was derived from a storage site in the neurons. A recent report using an ultrasensitive, highly specific, enzyme-amplified immunometric assay showed that
IL-1 concentrations higher than about $15 \mathrm{pg}$ are present in the normal rat hypothalamus (Hillhouse and Mosley, 1993). Since tissue homogenates could contain pro-IL-1, and pro-IL-1 has also been reported to be biologically active (Rosenwasser et al., 1986; Jobling et al., 1988), measurement of IL-1 in tissue homogenates using the bioassay may demonstrate levels higher than those determined using the ultrasensitive, highly specific immunometric assay.

Minami et al. (1991) reported that IS induced IL-1 $\beta$ mRNA in the rat hypothalamus at $30 \mathrm{~min}$ after the start of IS, which reached a maximum at $60 \mathrm{~min}$ and was still detectable, though at a decreased level, up to $120 \mathrm{~min}$. The cell responsible for inducing IL-1 $\beta$ mRNA with stimulation of the IS has not been identified. Our results are consistent with previous findings in regard to the time course (Fig. 3). It may be reasonable to consider the possible contribution of endogenous IL-1Ra to the IL-1 bioassay system, since the IL-1Ra is also present in normal brain (Licinio et al., 1991), is made by the same cells that make IL-1 (Arend et al., 1985), binds preferentially to type I IL-1 receptors, and blocks IL-1 effects (Eisenberg et al., 1990; Dinarello, 1991; Dinarello and Wolff, 1993). As it has been suggested that IL$1 \mathrm{Ra}$ acts endogenously on the brain as a protective agent (Relton and Rothwell, 1992), there is a possibility that IL-1 Ra is produced in the hypothalamus of the immohilized rat, synergistically, along with the production of IL-1. If this is the case, the IL-1 count could be underestimated by the bioassay. However, irrespective of the production of endogenous IL-1Ra, the important point is that the levels of IL- 1 activity are enhanced by IS in the hypothalamus.

In order to assess whether elevated IL-1 activity plays a role in stress responses, we administered IL-1Ra directly into the rat hypothalamus to block the effects of IL-1. Moreover, in order to exclude different responses due to IS among individuals, we compared the levels of monoamines between the side of the hypothalamus treated with IL-1Ra and the contralateral side treated with vehicle in the same rat. Io determine whether the administered doses of IL-1 Ra inhibited the IL-1 effects in the hypothalamus, the microdialysis cxperiments were carried out by taking the hrIL- $1 \beta$-activated NE release as an index of IL-1 effects. Since the administered doses of IL-1Ra were sufficient to inhibit elevated release of NE elicited by $1 \mathrm{ng}$ of hrIL-1 $\beta$ (Fig. 4), and the calculated IL-1 in response to IS was lower than $1 \mathrm{ng}$, we speculate that $2 \mu \mathrm{g}$ of IL-1Ra completely inhibited the monoamine-releasing effects of IL-1 in the hypothalamus.

As it has been reported that brain injury due to insertion of the microdialysis probe induces $\mathrm{LL}-1$ production for periods of 24-48 hr (Woodroofe et al., 1991), we may have to take into consideration the possibility that IL- 1 induced by the probe injury enhanced the release of NE. However, IL-1Ra administered by itself did not affect the basal release of NE in the anterior hypothalamus. Since the series of microdialysis experiments was completed vithin $24 \mathrm{hr}$ of probe insertion, even if the probe injury had elicited IL-1 production over this $24 \mathrm{hr}$ period, we consider any effect on the release of monoamine during the periods of experiments to be highly unlikely.

Using a microdialysis method, Pacak et al. (1992) indicated that exposure of rats to IS ir, $120 \mathrm{~min}$ increased NE levels to about six times the basal level: in the paraventricular nucleus of the hypothalamus. They also showed that dialysate DOPAC levels in the same region increased ouring IS. Shimizu et al. (1992), using a microdialysis technique, reported that IS rapidly increased the levels of 5-HT in the lateral hypothalamic area, and 
that the levels reached a maximum after $40 \mathrm{~min}$ of IS exposure. This maximum was about three times the basal level. We have also employed microdialysis to show that IS enhanced the levels of NE, DA, 5-HT, and their metabolites (Fig. 5A-G). 'I'hese results are consistent with those of previous investigators. In addition, our results on the IS-induced elevation of plasma ACTH are consistent with the established concept that there is a rapid and marked increase in plasma ACTH levels followed by a decline toward normal values despite the continuance of IS (Fig. $7 A-D$ ) (Yates and Maran, 1980; Makara et al., 1983). Since the magnitudes of responses induced by IS in rats which had been operated were within the same range as those of intact animals (Kvetnansky et al., 1976), we assume that damage due to the surgery was minimal and did not affect the responses.

The IS-induced elevations of hypothalamic NE, DA, and 5-HT levels, as well as plasma ACTH levels, were significantly inhibited by IL-1 Ra directly preadministered into the hypothalamus (Figs. 5A-G, 7A). These results are consistent with the view that stress responses, including the elevation of both monoamine release and ACTH secretion, are elicited by the effects of hypothalamic IL-1. Since intracerebral infusion of IL-1 $\beta$ near the paraventricular nucleus enhances $\mathrm{CRH}$ release no later than 5 min after infusion (Barbanel et al., 1990), we speculate that the elevated ACTH secretion may be due to increased $\mathrm{CRH}$ secretion in the hypothalamus stimulated by elevated hypothalamic IL-1. However, as it has been reported that IL-1 directly enhanced the secretion of ACTH from the pituitary gland (Bernton et al., 1987), the possibility remains that IL-1 produced in the hypothalamus directly affected the pituitary gland to increase ACTH secretion. In any event, it should be emphasized that the IS-induced increases in plasma ACTH levels were inhibited by administration of IL-1Ra into the hypothalamus.

The anterior hypothalamus is close to both the paraventricular nucleus and the median eminence, which contain the cells of origin and terminals of hypophysiotropic projections driving the pituitary-adrenal system. Since the precise site of the inhibitory effects of IL-1Ra could not be determined, we postulate that ncurons located close to both sites were involved in the effects of IL-1 Ra in the stress responses. The insertion of an incorrectly positioned probe, missing the targeted anterior hypothalamic area by not more than $1 \mathrm{~mm}$ laterally, caudally, or dorsally, failed to produce the effects of IL-1Ra (data not shown). We assume, therefore, that a narrow, very limited, area in the hypothalamus might be involved in stress responses.

The inhibitory effects of IL-1Ra on the IS-induced elevation of monoamine release and $\mathrm{ACTH}$ secretion were observed for the initial 20-30 min of IS (Figs. $5 A-G, 7 A$ ), whereas no significant increase in IL- 1 activity was detected during the same period (Fig. 3). The possibility remains that IL-1 enhanced hypothalamic release of monoamines and/or hormones at levels lower than those detected during earlier periods of IS. Therefore, we could not rule out the possibility that IL-1 increased locally causing hypothalamic neurons to release these substances. If so, there are two explanations: (1) induction of IL-1 based on translation from IL-1 mRNA occurred within the initial $20 \mathrm{~min}$ of IS; (2) immediate release of IL-1 from neurons.

To demonstrate whether early actuation of IL-1 effects is the mechanism underlying the observed IS-induced responses, IL$1 \mathrm{Ra}$ was administered immediately before or after the start of IS. Whereas $2 \mu \mathrm{g}$ of IL-1 Ra, which had been administered at 5 min before the start of IS, inhibited the elevation of monoaminc or ACTH, the same dose of IL-1Ra did not inhibit the elevations at approximately the time when the monoamine or ACTH levels had peaked, even at $5 \mathrm{~min}$ after the start of IS (Figs. $6 A-C, 7 B-$ $D$ ). These results suggest that the IL-1 effects responsible for monoamine release and $\mathrm{ACl}$ 'H secretion have been completed no later than $5 \mathrm{~min}$ after the start of IS. Furthermore, these results strongly suggest that IL-1, which has been found to preexist in the neurons, was promptly released by the IS, because there is no evidence from any cell type studied that IL-1 can he synthesized in $5 \mathrm{~min}$ or less.

Since the increased levels of hypothalamic NE and plasma ACTH were still observed from $60 \mathrm{~min}$ to $240 \mathrm{~min}$ after the initiation of IS, it is suggested that the initial release of IL-1 triggers sustained release of these monoamines and/or hormones. However, this raises two questions: (1) Why are maximal levels of IL-1 delayed irrespective of early exertion of its effects? (2) How is IL-1 produced from $60 \mathrm{~min}$ to $240 \mathrm{~min}$ after the start of IS involved in the stress response? The former observation may be explained by the possibility that early local release of IL-1 enhances induction of its own synthesis in the hypothalamus during the late periods, since IL- 1 can elicit its own synthesis in the brain (Spranger et al., 1990). The latter observation may be attributable to the IL-1 which has been produced playing roles in strengthening stress responses triggered by released IL1 . In the previous report, however, we found that hrIL-1 $\beta$ triggers the continuous release of NE and DA from neurons in the rat hypothalamus. If IL-1 naturally exerted an enhancing effect on the release of these catecholamines, one of the most interesting points focuses on why elevated monoamines or hormones are restored to the baseline level despite the effects of IL-1. We speculate that any events attenuating stress responses are involved in this restoration, and that the IL- 1 which had been produced may be involved in such a negative feedback mechanism.

In addition, increases in hypothalamic monoamines occurred despite preadministration of IL-1Ra (Fig. $5 A-G$ ). There are two possible explanations: (1) doses of IL-1Ra may be insufficient to inhibit elevations; (2) there are some neurons which can be activated by IS even without IL- 1 regulation. The first possibility could not be tested because of technical difficulties in measuring the monoamines when a larger dose of IL-1Ra was administered through the microinjection tube. But, if true, this would indicate that all hypothalamic neurons participating in IS-induced monoamine release are regulated by IL-1. The increase in plasma ACTH observed despite preadministration of a larger dose (20 $\mu \mathrm{g}$ ) of IL-1Ra (Fig. 7A) suggests that some neurons are activated by IS through the effects of factors other than IL-1. Other investigators also suggest that the mechanism of action of IL- $1 \beta$ on CRH mRNA appears to be distinct from that which is activated in response to an acute stress (Chover-Gonzalez et al., 1993). Therefore, we speculate that factors other than IL-1 are involved in stress responses.

Although the hypothalamus is the major site of IL-1 action in the brain, whether $\mathrm{IL}-1$ receptors are present in the hypothalamus remains controversial. Autoradiographic studies using radiolabeled IL-1 revealed specific binding sites (Katsuura et al., 1988; Takao et al., 1990), but such studies do not necessarily prove the presence of receptors in the brain (Ban et al., 1991). Inconsistencies between the results of ligand binding studies and immunohistochemical data have been reported for many peptides (Farrar et al., 1987; Herkenham, 1987). Rothwell (1991) claimcd that polymcrasc chain rcaction analysis fails to detect mRNA for the type I receptor in the rat hypothalamus. On the 
other hand, many in vitro experiments using hypothalamus ex plants have demonstrated the direct actions of monoamines and CRH (Berkenbosch et al., 1987; Sapolsky et al., 1987; Shintani et al., 1993). These findings provide a line of evidence for the existence of IL-1 receptors on hypothalamic neurons. When all members of the cytokine family and their receptors have been cloned, this apparent discrepancy might be resolved (Saper and Breder, 1992). Therefore, it is possible that the effects of IL-1 are mediated through an as yet unidentified type of IL-1 receptor in the hypothalamus.

Furthermore, it remains to be clarified whether the effect of hypothalamic IL-1 is directly related to peripheral stress responses including behavioral and physical changes. However, some portion of the peripheral changes occurring due to the central effects of IL-1 may be explained by neurohormonal responses caused by $\mathrm{CRH}$ oversecretion. Central injection of a CRH receptor antagonist or neutralizing antibody markedly inhibits IL-1-induced suppression of food intake (Uehara et al., 1989) and specific changes in behavior (Dunn et al., 1991), which resemble general stress responses (Uehara et al., 1989; Dunn et al., 1991; Johnson et al., 1992).

In summary, the results of this study suggest that stress-induced release of IL- 1 enhances the HPA axis as well as monoamine release in the hypothalamus. IL- 1 may be a regulator of stress responses, including behavioral, endocrine, and autonomic components, and the blockade of IL- 1 effects is potentially beneficial for protection from excessive stress responses.

\section{References}

Arend WP, Joslin FG, Massoni RJ (1985) Effects of immune complexes on production by human monocytes of interleukin-1 or an interleukin-1 inhibitor. J Immunol 134:3868-3875.

Ban E, Milon G, Prudhomme N, Fillion G, Haour F (1991) Receptors for interleukin-1 ( $\alpha$ and $\beta$ ) in mouse brain: mapping and neuronal localization in hippocampus. Neuroscience 43:21-30.

Banks WA, Kastin AJ (1992) The interleukins- $1 \alpha,-1 \beta$, and -2 do not acutely disrupt the murine blood-brain barrier. Int J Immunopharmacol 14:629-636.

Barbanel G, Ixart G, Szafarczyk A, Malaval F, Assenmacher I (1990) Intrahypothalamic infusion of interleukin- $1 \beta$ increases the release of corticotropin-releasing hormone (CRH 41) and adrenocorticotropic hormone (ACTH) in free-moving rats bearing a push-pull cannula in the median eminence. Brain Res 516:31-36.

Berkenbosch F, Oers JV, del Rey A, Tilders F, Besedovsky HO (1987) Corticotropin-releasing factor-producing neurons in the rat activated by interleukin-1. Science 238:524-526.

Berkenbosch F, Wolvers DA, Derijk R (1991) Neuroendocrine and immunological mechanisms in stress-induced immunomodulation. $J$ Steroid Biochem Mol Biol 40:639-647.

Bernton EW, Beach JE, Holaday JW, Smallridge RC, Fein HG (1987) Release of multiple hormones by a direct action of interleukin-1 on pituitary cells. Science 238:519-521.

Besedovsky HO, del Rey A, Klusman I, Furukawa H, Monge AG, Kabiersch A (1991) Cytokines as modulators of the hypothalamus-pituitary-adrenal axis. J Steroid Biochem Mol Biol 40:613-618.

Breder CD, Dinarello CA, Saper CB (1988) Interleukin-1 immunoreactive innervation of the human hypothalamus. Science 240:321324.

Chover-Gonzalez. AJ, Harbuz. MS, I Iightman SI. (1993) Fffect of adrenalectomy and stress on interleukin- $1 \beta$-mediated activation of hypothalamic corticotropin-releasing factor mRNA. J Neuroimmunol $42: 155-160$.

Dinarello CA (1991) Interleukin-1 and interleukin-1 antagonism. Blood $77: 1627-1652$

Dinarello CA, Wolff SM (1993) The role of interleukin-1 in disease. N Engl J Med 328:106-113.

Dinarello CA, Rosenwasser LJ, Wolff SM (1981) Demonstration of a circulating suppressor factor of thymocyte proliferation during endotoxin fever in humans. J Immunol 127:2517-2519.
Dunn AJ, Antoon M, Chapman Y (1991) Reduction of exploratory behavior by intraperitoneal injection of interleukin-1 involves brain corticotropin-releasing factor. Brain Res Bull 26:539-542.

Eisenberg SP, Evans RJ, Arend WP, Verderber E, Brewer MT, Hannum $\mathrm{CH}$, Thompson RC (1990) Primary structure and functional expression from complementary DNA of a human interleukin-1 receptor antagonist. Nature 343:341-346.

Farrar WL, Kilian PL, Ruff MR, Hill JH, Pert CB (1987) Visualization and characterization of interleukin-1 receptors in brain. $\mathbf{J}$ Immunol 139:459-463.

Giulian D, Tapscott MJ (1988) Immunoregulation of cells within the central nervous system. Brain Behav Immunol 2:352-358.

Herkenham M (1987) Mismatches between neurotransmitter and receptor localizations in brain: observations and implications. Neuroscience 23:1-38.

Hillhouse EW, Mosley K (1993) Peripheral endotoxin induces hypothalamic immunoreactive interleukin- $1 \beta$ in the rat. $\mathrm{Br} \mathrm{J}$ Pharmacol 109:289-290.

Jobling SA, Auron PE, Gurka G, Webb AC, McDonald B, Rosenwasser LJ, Gehrke L (1988) Biological activity and receptor binding of human prointerlcukin-1 $\beta$ and subpeptides. J Biol Chem 263:16372.

Johnson EO, Kamilaris TC, Chrousos GP, Gold PW (1992) Mechanisms of stress: a dynamic overview of hormonal and behavioral homeostasis. Neurosci Biobehav Rev 16:115-130.

Katsuura G, Gottschall PE, Arimura A (1988) Identification of a highaffinity receptor for interleukin- $1 \beta$ in rat brain. Biochem Biophys Res Commun 156:61-67.

Kvetnansky R, Mitro A, Palkovits M, Brownstein M, Torda T, Vigas M, Mikulaj L (1976) Catecholamines in individual hypothalamic nuclei in stressed rats. In: Catecholamines and stress (Usdin E, Kvetnansky R, Kopin IJ, eds), pp 39-50. Oxford: Pergamon.

Lechan RM, Toni R, Clark BD, Cannon JG, Shaw $\Lambda \mathrm{R}$, Dinarello CA, Reichlin S (1990) Immunoreactive interleukin-1 $\beta$ localization in the rat forebrain. Brain Res 514:135-140.

Licinio J, Wong ML, Gold PW (1991) Localization of interleukin-1 receptor antagonist mRNA in rat brain. Endocrinology 129:562-564.

Makara GB, Palkovits M, Szentagothai J (1983) The endocrine hypothalamus and the hormonal response to stress. New York: Scientific and Academic Editions.

Minami M, Kuraishi Y, Yamaguchi T, Nakai S, Hirai Y, Satoh M (1991) Immobilization stress induces interleukin- $1 \beta$ mRNA in the rat hypothalamus. Neurosci Lett 123:254-256.

Nakaki T, Saito M, Nakadate T, Kato R (1981) Acute physical dependence induced by continuous intravenous infusion of morphine or meperidine in the rat. Psychopharmacology 73:215-218.

Pacak K, Armando I, Fukuhara K, Kvetnansky R, Palkovits M, Kopin IJ, Goldstein DS (1992) Noradrenergic activation in the paraventricular nucleus during acute and chronic immobilization stress in rats: an in vivo microdialysis study. Brain Res 589:91-96.

Relton JK, Rothwell NJ (1992) Interleukin-1 receptor antagonist inhibits ischemic and excitatory neuronal damage in the rat. Brain Res Bull 29:243-246.

Rosenwasser LJ, Webb AC, Clark BD, Irie S, Chang L, Dinarello CA, Gehrke L, Wolff SM, Rich A, Auron PF, (1986) Expression of biologically active human interleukin- 1 subpeptides by transfected simian COS cells. Proc Natl Acad Sci USA 83:5243-5246.

Rothwell NJ (1991) Functions and mechanisms of interlcukin 1 in the brain. Trends Pharmacol Sci 12:430-436.

Saper CB, Breder CD (1992) Endogenous pyrogens in the CNS: role in the febrile response. Prog Brain Res 93:419-429.

Sapolsky R, Rivier C, Yamamoto G, Plotsky P, Vale W (1987) Interleukin-1 stimulates the secretion of hypothalamic corticotropin-releasing factor. Science 238:522-524.

Seckinger P, Dayer JM (1987) Interleukin-1 inhibitors. Ann Inst Pasteur Immunol 138:486-488.

Shimizu N, Take S, Hori T, Oomura Y (1992) In vivo measurement of hypothalamic serotonin release by intracerebral microdialysis: significant enhancement by immobilization stress in rats. Brain Res Bull 28:727-734.

Shintani F, Kanba S, Nakaki T, Nibuya M, Kinoshita N, Suzuki E, Yagi $G$, Kato R, Asai M (1993) Interleukin- $1 \beta$ augments release of norepinephrine, dopamine and serotonin in the rat hypothalamus. $\mathrm{J} \mathrm{Neu}-$ rosci 13:3574-3581

Shiozawa M, Yamashita S, Aiso S, Yasuda K (1989) A monoclonal antibody against human kidney gamma-glutamyl transpeptidase: 
preparation, immunochemical, and immunohistochemical characterization. J Histochem Cytochem 37:1053-1061.

Spranger M, Lindholm D, Bandtlow C, Heumann R, Gnahn H, NäherNoé M, Thoenen H (1990) Regulation of nerve growth factor (NGF) synthesis in the rat central nervous system: comparison between the effects of interleukin-1 and various growth factors in astrocyte cultures and in vivo. Eur J Neurosci 2:69-76.

Takao T, Tracey DE, Mitchell WM, De Souza EB (1990) Interleukin-1 receptors in mouse brain: characterization and neuronal localization. Endocrinology 127:3070-3078.

Uehara A, Sekiya C, Takasugi Y, Namiki M, Arimura A (1989) An- orexia induced by interleukin-1: involvement of corticotropin-releasing factor. Am J Physiol 257:R613-R617.

Wakabayashi G, Gelfand JA, Burke JF, Thompson RC, Dinarello CA (1991) A specific receptor antagonist for interleukin 1 prevents Escherichia coli-induced shock in rabbits. FASEB J 5:338-343.

Woodroofe MN, Sarna GS, Wadhwa M, Hayes GM, Loughlin AJ, Tinker A, Cuzner ML (1991) Detection of interleukin-1 and interleukin-6 in adult rat brain, following mechanical injury, by in vivo microdialysis: evidence of a role for microglia in cytokine production. J Neuroimmunol 33:227-236.

Yates FE, Maran JW (1980) Stimulation and inhibition of adrenocorticotropin release. Washington, DC: American Physiological Society. 